$I^{2}$ N THE LAST ISSUE OF THE JOURNAL, I SET OUT MY own views concerning the Interim report from the Inquiry established by the Government of the United Kingdom to explore the events occurring at Bristol Royal Infirmary in the late 1980 's and early 1990's. In that editorial, I praised the content of the interim report, and commented how it was of importance to all those concerned with cardiology in the young. Through my appearances at the Inquiry, and because of other connections with the happenings at Bristol, I have been fortunate to meet Maria Shortis, who lost one of her own children at Bristol during the period under inquiry. Maria was a founder member of the Bristol Heart Children Action Group. Since then, she has been stimulated to establish a much larger organisation called Constructive Dialogue for Clinical Accountability. The title of this organisation is self explanatory. Maria believes that doctors need to be more accountable, but that this accountability needs to be established through constructive dialogue. She is now working hard to establish this group as a charitable foundation. In the meantime, she is still deeply concerned with the aftermath of
Bristol. I shared my own editorial with Maria prior to its publication, and she kindly agreed to respond so as to provide a view from the side of the parents. Her opinions, and those of other parents from Bristol, are encapsulated in the response printed beneath. Like the implications of the interim report, the views expressed by Maria and her friends extend far beyond Bristol and the United Kingdom. It may well be that practise in the United Kindgom, particularly the way that doctors deal with children and their parents, is unique. It may also be that the lack of communication highlighted by Maria in her response is similarly confined to those practising in the United Kingdom. If this is the case, then we in the United Kingdom need to ensure that our own activities match those from elsewhere. If it is not the case, then everyone needs to pay attention to the views expressed. Either way, this matter continues to require our urgent attention. As always, we are ready to publish the views of any or all who wish to comment on this crucial issue.

Robert H. Anderson Editor-in-Chief

\title{
The issue of retention of organs - an informed view from Bristol parents
}

I N HIS EDITORIAL PUBLISHED IN THE JULY ISSUE OF the Journal, ${ }^{1}$ Professor Anderson has written at length about the Bristol Inquiry, its terms of reference and, in particular, the issue of retention of organs. He addresses the dilemma faced by the medical profession in rebuilding the trust of the public whilst enabling research and education to continue using "human material" for the intended benefit of saving the lives of future patients. In this article, I hope to highlight the dilemma involved for us as parents who have lived through the agony, and have endured the reality of being caught up in the paternalistic approach of the medical profession.

In his article, Professor Anderson quotes Professor Michael Green's evidence to the inquiry “... it was felt that if organs were to be retained, relatives should not be further distressed by being presented with a list of organs that might be retained". 2 It is an understandable view, but one full of assumption, and one which firmly keeps the parents in the dark and uninformed. These comments should not be seen as an overt criticism of Professor Green, but understood in the context and culture of their time.

I hope that the interim report, which highlights this attitude of paternalistic benevolence, namely making decisions for parents who are perfectly capable of making these decisions themselves, serves as a catalyst for change.

Is the interim report only concerned with the parochial view of what happened in Bristol? The 
parents with whom I spoke to this week think not. Having read through the 69 recommendations, they are unanimous in their view that the report is thorough, concise, and covers every aspect of both coroner's and hospital post mortems.

They would like to see the recommendations applied nationally so that other parents facing the possible death of their child do not have to suffer the mental anguish which they have already gone through, this being the discovery that the organs from their children had been retained and used for research without their knowledge. The interim report states "There is a real sense in parents of exclusion, of being caught up in a system in which they play no role and have no say, when it is their child who has just died. This is perhaps exacerbated by the involvement of the coroner or his office, as these people are not previously involved with the family and whose role may be unclear to the parents".?

Retention of organs is, by its very nature, an emotive issue. There is a real dilemma on the part of the medical profession to treat relatives of the dead in a proper way, but also to make use of the "riches" which a dead body can offer. The first two recommendations of the interim report recognise the need for parents to be central in the decisionmaking process after the death of a child, whilst also understanding the role of education and research in the use of human material.

The first recommendation states "The ruling principle in the removal, retention, use and disposal of human material must be the respect for the dead child and for the concerns and, to the extent allowed by the law, the wishes of the parents".

The Bristol story has highlighted just how little information parents were given in regard to the retention of their children's organs. The second recommendation states, "There is benefit to be gained, in terms of developing the understanding and treatment of disease, from the use of human material. Such benefit must only be obtained, however, with the informed co-operation of parents". 2

How is that co-operation going to be attained now in view of the distress and anguish which so many parents are still going through on a national scale to determine how many organs of their dead child have been retained?

Brenda Rex lost her son, Stephen, in 1986. Fourteen years later, it has taken her 18 months to discover the extent of the human material that the pathologists have retained. Her husband rather poignantly comments "I do not know where to lay flowers for my son any more. Do I put them on his grave, or lay them outside the pathology department?" Brenda is very pragmatic and says, "All information regarding post mortems must be given to parents/guardians/relatives in writing."

She argues, "At the time of death it is difficult to take in all that has to happen"

I ask her, and another mother, Lorraine Pentecost, whose son Luke died in 1985, whom they hold responsible for informing them about the post mortem process. "It should be the consultant surgeon or cardiologist," they both agree. "In particular the surgeon, as he carried out the surgery on our children, and we put our trust in him"

They realise, of course, that it is difficult to speak about the issue of removal and retention of organs at a time when a child has died. They think the process should start earlier. Part of the inevitability of cardiac surgery, or any life-saving surgery, is the risk of survival. "Of course, as parents we all want our children to survive" says Brenda "but we shouldn't be shielded from the possibility that they may die". When this tragically happens, parents need to be treated with respect, and to know that their dead children continue to be treated with respect, and honoured appropriately.

It shouldn't be forgotten that the death of a child also affects the hospital team of nurses and doctors who have been involved in the child's care. Working together, as the report recommends, can only be in the best interest of all parties.

In 1987, my daughter Jacinta died suddenly at home following cardiac surgery at the Bristol Royal Infirmary. She was almost 10 weeks old. She had five major malformations in her heart, and had rapidly lost weight and suffered complications following surgery. Her death, although sudden, came as no surprise to me, having watched her struggle to live. A post mortem was not necessary in her case, but I found myself requesting one because of the response of the consultant cardiologist to her death. He expressed such surprise at her sudden death that I felt obliged to ask for an autopsy to establish that I, as her mother and carer, had not contributed to her death in any way.

The interim report states that, between 1984 and 1995, 265 post mortems were carried out on children who died following cardiac surgery. Of these, 220 were performed at the behest of the coroner, and 45 were hospital postmortems. ${ }^{2}$

Jacinta underwent a hospital postmortem. No one thought to explain to us that there were two types of postmortem. Nor did anyone tell me what I should do to ensure her body was returned to the undertakers. Her body was removed from our house the morning after her death and sent to the hospital. My husband had decided to make her coffin and I wanted to dress her for her burial. I 
wanted to make arrangements for her burial and phoned the office of the coroner, as I was unaware of the two different legal aspects of postmortem. I spoke to the coroner, who asked me to wait whilst he looked through his list of dead bodies to se if my daughter was included. When he told me that he didn't have her body, I momentarily panicked, thinking that they had perhaps lost her. He realised immediately that she must be a hospital postmortem, and advised me to ring the pathology department. By the time I did this, she was already on her way back to the undertakers.

I use this experience to highlight the need for clear lines of communication and information to be given to parents. I formed the view that health professionals didn't really know, or have any training, in dealing with parents whose children had died.

This led to poor lines of communication or information, all of which are really important at the time of such acute grief.

When I asked the other parents about their individual experiences, they all talked about having felt patronised in the way they were treated by clinicians. Some expressed the view that they were made to feel like second-class citizens. This cannot be overemphasised, as many parents have voiced it. The way in which the medical profession tends to treat people according to their social status is hurtful, and needs to be addressed. Some parents never spoke to the surgeon. They were counselled only by nurses. One mother told me how she had returned to the Bristol Royal Infirmary just a few minutes after she had been told that her son had died, to ask someone what she should do next, as she had never had a child die before. There were no personnel around. Eventually, she stopped a young doctor in a corridor to find out the due process.

As one mother said "I wasn't even told that my son had a heart problem, let alone that he needed a heart operation" She was sent home with him, and told to treat him as a normal child. This kind of interaction or misinformation is unforgivable, and perhaps to some degree explains why there was such an outcry in Bristol about the issue of retention of organs. Even though some of us were aware that Bristol had a large collection of hearts, the information dripped out very slowly. As a result, it angered and devastated parents. Every parent expected a postmortem to involve looking at their child's organs, but no one suspected that not only the heart, but other organs had also been retained without their knowledge. It is hard to imagine that any of this information would have come to light without the constant questioning of parents once the present public inquiry was underway. Eventually, in May 1999, we received a letter telling us that Jacinta's heart had been retained. We had suspected this in 1987 . We had then decided that, if this was the case, we felt alright about Jacinta's heart being used for education and research. What we didn't know was that her brain had also been retained, and then disposed of under the Human Tissue Act of 1961. On learning this, my husband commented, "We should have been informed of this before they disposed of her brain"

Informed consent is the crucial issue. Not one of the Bristol parents had been told that their children's organs would be retained following postmortem. Every parent to whom I have spoken realised that a postmortem would establish the cause of death, and would also further medical research and enable surgeons to improve their practice.

In his editorial, Professor Anderson speaks of this issue and says "My purpose in giving this evidence (to the inquiry) was to highlight the huge advantages which, in my opinion, had accrued from the availability of the post mortem material held in these (heart) collections." $\mathrm{He}$ continues, "The major reason for our wishing to retain the organs, of course, was our desire to use them to increase our knowledge, and hopefully improve our strategies for future diagnosis and treatment. We failed to recognise the need to do this in partnership with the bereaved parents." Professor Anderson has put his finger on the problem, namely the failure to respect and to involve the parents in this process. How can that failure have occurred? From the perspective of the parents it is all too simple. "They weren't interested in us," says Lorraine "They didn't think to ask. If I borrow something I normally ask permission and then I return it when I have finished with it. All they had to do was ask our permission"

The group of parents look at one another and ask, "Did the postmortems really help in saving other children's lives?" The answer betrays their scepticism. "I imagine" says one "That they just kept the hearts in a big jar and left them on the shelf"

When I ask them what their response might have been had they been informed of the process, the reply is unanimous. "Had we been treated with respect, and made part of the decision-making process, we wouldn't have had this huge public outcry, and we could have known that some good was coming out of our personal tragedy"

As it is, our experiences have unleashed so much unnecessary grief. Many marriages have broken down, and lives have been taken in some cases. "If 
only they could understand the emotional isolation we are left in when they don't tell us or provide us with the information we need". It is so important for the medical profession to offer us the choice to have information. A great amount of mistrust has been created due to the lack of openness and transparency within the medical profession

Lorraine comments further "All parents who wish to know about postmortem and the retention of organs should be helped to find out. It has taken me a long time to discover the truth about Luke, and I wouldn't wish that mental anguish on anyone". Lorraine and Brenda insist that pathologists should be clear and open to parents and relatives about the research and education that is cartied out. They see no value in established collection of hearts now being destroyed. It is crucial that those parents who wish to have the organs of their children returned for burial or cremation are able to do so. They also insist that there are parents who may not wish to go back over the past to find out what has happened to the organs, and they should also have their views respected.

As Brenda and Lorraine read through the recommendations of the interim report, they look to the future. It is with a sense of pride that they realise that their courage in giving harrowing evidence to the inquiry, along with other parents, has enabled the Inquiry Panel, led by Professor Ian Kennedy, to deliver such an excellent report. They and all other Bristol parents, hope the Chief Medical Officer will fully endorse the recommendations, apply them nationally, and introduce the necessary legislation to ensure that future parents and relatives are saved the unnecessary grief and mental anguish which so many parents have been put through under the auspices of "benevolent paternalism". It remains to be seen in practice how long the necessary changes in culture and attitude will take.

\section{Acknowledgements}

I am indebted to Lorraine Pentecost, along with Brenda and Phil Rex, for the contributions they made to my article. I also express my thanks to all the other Bristol parents who formed part of the dialogue. We all offer our thanks to the Editors and Publishers of Cardiology in the Young for this opportunity to give our views, and we look forward to continuing the dialogue.

$$
\begin{array}{r}
\text { Maria Shortis } \\
\text { Director, Constructive Dialogue for Clinical } \\
\text { Accountability. } \\
\text { Campaigner and Founder Member - Bristol Heart } \\
\text { Children Action Group } \\
54 \text { Alma Vale Road } \\
\text { Clifton } \\
\text { Bristol BS8 } 2 H S \\
\text { Tel: O1179092427 } \\
\text { e-mail: mariashortis@cdca.freeserve.co.uk }
\end{array}
$$

\section{References}

1. Anderson RH. Arrogance born of indifference? Cardiol Young 2000;10: 297-298

2. The Inquiry into the management of care of children receiving complex heart surgery at the Royal Bristol Infirmary. Interim report. Removal and retention of human material. The Bristol Royal Infirmary Inquiry. Central Office of Information. May 2000 